\title{
52. Kapitel. Bildung krimineller Verbände
}

Die $\S \S 127-129$ b bestrafen die Bildung bewaffneter, krimineller und terroristischer Verbände. Während die $\S 127$ und 129 ältere Tatbestände darstellen, wurde der mittlerweile völlig unübersichtlich gewordene § 129a erst im Jahre 1976 im Zuge der Auseinandersetzungen mit dem RAF-Terrorismus geschaffen, seither vielfach geändert und im Jahre 2002 durch $\S 129 \mathrm{~b}$ auf ausländische Vereinigungen ausgedehnt. Er fungiert weniger als traditionelle Strafrechtsnorm, die Verbote bewehrt und deren Übertretung sanktioniert, sondern vielmehr als strafprozessuale Anknüpfungsbestimmung für Eingriffs- und Zuständigkeitsregelungen (vgl. die $\S \S 100 \mathrm{a}$ II Nr. $1 \mathrm{~d}$ ), 100b II Nr. 1 b), 100c I Nr. 1, 112 III StPO, § 120 I Nr. 6 GVG), wenn sich der jeweils erforderliche Grad eines Tatverdachts einer anderen Katalogtat noch nicht recht darstellen lässt.

Eine nähere Darstellung erfolgt auf ET 52-01.

Ergänzende Information Die elektronische Version dieses Kapitels enthält Zusatzmaterial, das berechtigten Benutzern zur Verfügung steht. https://doi.org/10.1007/978-3-662-63967-2_52 